\title{
Desde la filosofía hacia el pensamiento emergente en el desarrollo de los procesos investigativos
}

\section{From philosophy to emerging thinking in the development of research processes}

\author{
Abel Rodríguez \\ abelantonioo@gmail.com \\ Universidad Nacional Experimental Sur del Lago \\ Venezuela \\ https://orcid.org/0000-0001-8712-2200
}

Recibido: 06 de octubre del 2018

Aprobado: 30 de octubre del 2018

\section{RESUMEN}

El objetivo de este artículo es demostrar la influencia de las corrientes filosóficas del pensamiento antiguo, medieval, moderno y contemporáneo; en los enfoques epistémicos o paradigmas investigativos tradicionales y emergentes, y estos a su vez en el desarrollo de los procesos investigativos de nuestro contexto científico. Dentro del marco metodológico, hemos utilizado la investigación de tipo documental y de carácter interpretativo y descriptivo, empleando como método de análisis, el análisis del discurso, el cual nos permitió establecer algunas conclusiones en el marco del ser de la investigación, entre estas; existe una influencia y correlación entre las Corrientes filosóficas del pensamiento antiguo, medieval, moderno y contemporáneo, y los enfoques epistémicos 0 paradigmas investigativos tradicionales y emergentes, asimismo, estos en el desarrollo de los procesos investigativos de nuestro contexto científico.

Descriptores: filosofía; corrientes filosófica; estilos de pensamientos; enfoques epistemológicos; procesos investigativos.

\section{ABSTRACT}

Philosophers and scientists have approached science and research according to their style of thought, expressed in a set of convictions developed in depth in the framework of science, research and scientific knowledge, in this sense, the perception of science will correspond to such thought styles; and these to the epistemological approaches. The objective of this paper is to demonstrate the influence of the philosophical currents 
of ancient, medieval, modern and contemporary thought; in epistemic approaches or traditional and emerging research paradigms, and these in turn in the development of the research processes of our scientific context. Within the methodological framework, we have used documentary research of an interpretative and descriptive nature, using as an analysis method, discourse analysis, which allowed us to establish some conclusions within the framework of the research being, between these; There is an influence and correlation between the philosophical currents of ancient, medieval, modern and contemporary thought, and epistemic approaches or traditional and emerging research paradigms, likewise, these in the development of the investigative processes of our scientific context.

Descriptors: philosophy; philosophical currents; styles of thoughts; epistemological approaches; investigative processes.

\section{INTRODUCCIÓN}

El hombre desde y, en el devenir de su existencia se ha propuesto conocer, entender, interpretar, significar, conceptualizar, etc., -el mundo que lo rodea-, sobre este interés ha dilucidado e interactuado con las cosas que lo componen, con el objeto de determinar la esencia que la constituye, -el porqué de las cosas-, además de conocerse así mismo, en este contexto se apertura la filosofía, el amor por el saber o la sabiduría. En derivación a esto, surge la epistemología o teoría del conocimiento, entendida como la "Doctrina de los fundamentos y métodos del conocimiento científico" (Real Academia Española, 2001); esta es considerada como una rama de la filosofía, su propósito fundamental es el estudio del conocimiento en su esencia. En este escrito abordaremos de forma sucinta los siguientes apartados; 1 . Contexto ontológico; 2 . El término filosofía, 3. Las corrientes filosóficas del pensamiento antiguo y medieval y, su influencia en los enfoques epistémicos o paradigmas investigativos tradicionales y emergentes, 4. Las corrientes filosóficas del pensamiento moderno y contemporáneo y, su influencia en los enfoques epistémicos o paradigmas investigativos tradicionales y emergentes, 5. La Influencia del pensamiento emergente en el desarrollo de los procesos investigativos, 6 . Metodología aplicada, 7. Conclusiones. 


\section{Contexto ontológico}

En el devenir de la filosofía y ciencia, se ha construido diversos conocimientos en disimiles áreas del saber, constituyéndose esto en uno de los medios para la resolución de los problemas propios de la humanidad. Sin embargo, el afán desmedido del hombre por generar nuevos conocimientos a partir de los existentes o inéditos con el mismo propósito, han ocasionado algunos excesos al momento de realizar la investigación, a saber, hacen uso simultaneo de manera inconscientemente de algunos enfoques epistemológicos en el proceso investigativo, perdiendo de esta forma secuencia, claridad y concreción en los resultados del hecho investigado, además, carencia en la delimitación del enfoque filosófico y epistémico propio de la investigación.

En este sentido, antes de incursionar en una investigación es ineludible conocer la influencia o el marco filosófico y epistemológico en la que está inmersa; en este contexto es preciso expresar, es posible la vinculación de algunos enfoques filosóficos y epistemológicos, aplicando racional y adecuadamente el paradigma ecléctico, procurando la inexistencia de las divergencias.

En este punto nos formulamos la siguiente interrogante; ¿Existe influencia de las corrientes filosóficas del pensamiento antiguo, medieval, moderno y contemporáneo; en los enfoques epistémicos o paradigmas investigativos tradicionales y emergentes, y estos a su vez en el desarrollo de los procesos investigativos de nuestro contexto científico?

En derivación a la interrogante antes formulada, nos planteamos el siguiente objetivo; Demostrar la influencia de las corrientes filosóficas del pensamiento antiguo, medieval, moderno y contemporáneo; en los enfoques epistémicos o paradigmas investigativos tradicionales y emergentes, y estos a su vez en el desarrollo de los procesos investigativos de nuestro contexto científico. 


\section{El término filosofía}

El significado etimológico del término filosofía es "amor a la sabiduría", en ocasiones es traducido "amor al saber". Los griegos inventores del término establecieron uso disimiles entre el saber y sabiduría; el primero hace referencia a un conocimiento teórico y, el segundo a su vez al conocimiento teórico y práctico inferido al sabio (Ferrater, 1994). Partiendo de la etimología del término, filosofía es el sentimiento eros -amor- y la atracción que experimenta el hombre hacia -el verdadero conocimiento que envuelve la realidad del mundo que lo rodea-. Es una búsqueda constante de la verdad y esencias de las cosas, movida por el amor al conocimiento teórico y teórico-práctico. Esto originó las corrientes filosóficas del pensamiento antiguo y medieval.

\section{Las corrientes filosóficas del pensamiento antiguo y medieval y, su influencia} en los enfoques epistémicos o paradigmas investigativos tradicionales $y$ emergentes

El pensamiento antiguo filosófico lo podemos ubicar geográficamente en Grecia y, datar aproximadamente entre los fines del siglo VII a.c y IV D.C. Según Marías (1980) existieron distintos periodos, entre estos. El Presocráticos entre lo siglo VII y V antes de Cristo, algunos de sus representantes son Tales, Anaximandro y Anaxímenes, estos establecieron la totalidad del mundo -la naturaleza-, -el cosmo- como principio activo originador de todas las cosas. Otro presocrático influyente y de importancia significativa fue Parménides con pensamiento contrario a los anteriores descubre la metafísica y ontología, no aborda las cosas estrictamente, sino las cosas en cuanto son, a saber, como entes. Este periodo Abbagnano (1994) lo identificó como el cosmológico, en él se presenta la unidad que garantiza el orden del mundo y, el conocimiento del ser humano. El periodo sofista y Sócrates entre el siglo V y IV, en este se inicia una nueva fase de la filosofía griega caracterizada fundamentalmente en la mirada del hombre sobre sí mismo y, no la preocupación del mundo, los sofista de relevancia son Hipias, Pródico, Eutidemo y, sobre todo, Protágoras y Gorgias, esencialmente plantearon la idea de lo 
que el hombre debe ser, el hombre sabio poseedor del noüs -saber, pensamiento-, -el buen ciudadano- su argumentación es a partir de lo abordado anteriormente en la filosofía, lo hacen a través de la retórica, en hablar bien sin importar la verdad. Mientras que Sócrates plantea la necesidad que cada cual conozca su areté -virtud-.-conócete a ti mismo- este imperativo moral socrático establece la posición del hombre de sí mismo. Este periodo Abbagnano (1994) lo señalo como antropológico.

El periodo Platón-Aristóteles entre los siglos IV y III, Platón propone la -idea- como el supuesto del conocimiento, el verdadero ser de las cosas y la visión de las cosas como tales y. Aristóteles desarrolla un pensamiento de rasgo naturalista y realista, en este el conocimiento se obtiene mediante la experiencia; ambos plantean la relación del hombre y el ser y, el valor del hombre. Este periodo Abbagnano (1994) lo marca como ontológico. Periodo ideal del sabio entre los siglos III A.C y IV D.C, unos de su exponente emblemático fue Diógenes el Cínico, surgen disimiles corrientes filosóficas: El Estoicismos, proponen lo moral del hombre, son sensualista, materialista, naturalista, está última regida por el principio de la razón, Epicureismo promueven un modo de vida, es materialista-atomista. Ecepticismo centra su filosofía en -el hombre no se fía-. Eclecticismo su filosofía radica en el compromiso y conciliación, toma de aquí y de allá, con el objeto de formar sistemas que superen las divergencias más profundas; estas corrientes centran su atención en la conducta humana. Este periodo Abbagnano (1994) lo identifica como ético. A la fecha data la filosofía antigua, esta apertura el devenir filosófico a la medieval.

La filosofía medieval se desarrolla en la edad media, aproximadamente en el siglo II al $X V$, en esta surge un hecho de importancia significativa nace Cristo, su pensamiento influenció la filosofía medieval y marcó la historia de la humanidad para siempre, al plantear una nueva visión del mundo. En este periodo surge el cristianismo sobre la base de una idea nueva, que establece la existencia del mundo y el hombre por medio de la creación, siendo Dios el autor. Las corrientes filosóficas en este periodo que a su vez son etapas, son; Patrísticas y Escolásticas, en la primera tenemos como 
representante a Orígenes y San Agustín, en la segunda a San Anselmo, Santo Tomás, Duns Scoto. En ambas, se pretende establecer una síntesis entre fe-religión y razón, en este sentido es comprender la revelación divina -DIOS- a través de la -razón humana-. Este periodo Abbagnano (1994) lo alude al religioso. Las corrientes filosóficas antiguas y medievales aperturaron el camino a los paradigmas investigativos tradicionales y emergente.

Es evidente la influencia de las corrientes filosóficas antiguas y medievales en los paradigmas investigativos tradicionales y emergentes, por poseer estos algunos rasgos distintivos propios de tales corrientes. En este sentido, el término filosofía -amor al saber y a la sabiduría- ha transcendido desde la antigüedad hasta la actualidad. Platón afirma, no se logra hacer filosofía sino por el éros; Aristóteles plantea que es una cierta philia, San Agustín es dada por la caritas, Spinoza doce siglo después la define como el amor Dei inteüectualis y, Ortega perteneciente a nuestra era y siglo, la considera como la -ciencia general del amor-. Existen disimiles concepciones o definiciones del término, sin embargo, todas son generada por el amor al conocimiento -el saber-.

Partiendo desde la antigüedad, este amor por el saber ha propiciado el surgimiento e influenciado los paradigmas investigativos tradicionales y emergentes. Según Thomas Kuhn (1971) paradigma, es el conjunto de leyes derivadas del trabajo científico, la formulación de teorías, la aplicabilidad e instrumentos de la ciencia o métodos que se constituye en un resultado paradigmático, a saber, en un modelo o patrón aceptado, surgido de las investigaciones científicas que su resultante es la ciencia normal y, Padrón (2014) considera a los paradigmas equivalente a 'escuela', 'corriente' o 'movimiento' en la historia anecdótica de la cultura humana. A saber, son sucesiones de estilos de pensamientos y enfoques epistemológicos, que resurgen en una época determinada en la construcción y validación del conocimiento científico con ismo o posturas de pensamientos distintas, sin embargo, son iguales o similares.

Padrón (2014) establece tres estilos de pensamiento: 1) Inductivo concreto, en este son utilizado los sentidos, la percepción sensorial, los mecanismos de constatación 
fáctica, aquí podemos ubicar a Diógenes el Cínico, entonces, este estilo de pensamiento lo podemos situar en la filosofía antigua -Greiga- en el periodo Ideal del sabio; 2) Deductivo abstracto, se utiliza la razón, los argumentos, la deducción, los mecanismos de razonamiento, en este estilo podemos identificar a Aristóteles perteneciente a la filosofía antigua -Griega- y, en la filosofía medieval, a Orígenes en el periodo Patrístico y, San Anselmo, Santo Tomás y Duns Scoto, en el periodo escolástico; 3) Intuitivo vivencial, en este tercero, a Platón de la filosofía antigua Griega- y, San Agustín de la filosofía medieval en el periodo patrístico.

Es indudable el resurgimiento de los estilos de pensamientos en el devenir de la historia de la filosofía, el conocimiento científico y, la ciencia, estos estilos forjaron los distintos enfoques epistemológicos, que de igual forma, han resurgido en el devenir de la historia de la ciencia. Hernández y Padrón (1997) en correspondencia a los tres estilos de pensamientos, proponen tres enfoques epistémicos, al igual que los estilos de pensamiento, ubicaremos a los autores de la filosofía antigua y medieval identificado con cada enfoques, sin embargo, no mencionaremos los periodos por estar expuesto anteriormente en el apartado de los estilos de pensamiento: 1) Empirismo, hace uso de la Inducción (experiencia controlada, explicación), este enfoque está vinculado al estilo -inductivo concreto- en este estuvo inmerso Diógenes el Cínico; 2) Racionalismo, utiliza la Deducción (modelación lógica, explicación), este está en correspondencia al estilo -Deductivo abstracto- Aristóteles y Descartes, fundamentaban su filosofía en el marco de este enfoque; 3. Vivencialismo, alude a la Intuición (experiencia vivida, comprensión), este último está relacionado con el estilo Intuitivo vivencial-, la filosofía de Platón y San Agustín, era propia de este enfoque.

Estos enfoques epistémicos son mencionados en algunos textos especializados como paradigmas tradicionales. Lo significativo no sería la denominación -enfoques o paradigmas-, sino, la influencia de la filosofía antigua y medieval en la construcción de las disimiles escuela, corrientes de pensamientos o movimiento, vista en el uso de estas filosofías como referente en la búsqueda del saber o conocimiento científico, 
derivados en estos enfoques o paradigmas tradicionales, tal como lo expusimos en los apartados anteriores. Sin lugar a dudas, con el desarrollo de la filosofía antigua y medieval y, su prosecución en el devenir de la historia de la ciencia, fue posible el surgimiento de los enfoques o paradigmas tradicionales antes mencionados.

Posterior a los enfoques o paradigmas tradicionales, han surgidos otros, estos son considerados emergentes, solo por poseer una denominación novedosa, sin embargo, conservan en esencia la filosofía antigua y medieval, tal es el caso del conductismo $\boldsymbol{y}$ el constructivismo. El conductismo se fundamenta en la conducta observable, parte de la relación causa-efecto, a saber, un estímulo y una respuesta, además, busca que las conductas sean medidas y controladas; estos rasgos están vinculados a algún enfoque epistémico o paradigma. El conductismo posee una expresión clara del Empirismo-Inductivista, este tiene su génesis en la filosofía antigua, en el periodo ideal del sabio, uno de su exponente significativo como lo mencionamos anteriormente fue Diógenes el Cínico. El constructivismo se basa en el Sujeto, lo significativo del conocimiento no está en la realidad en sí misma, sino en la autonomía del sujeto al desarrollar actividades que le permite construir la realidad, esto posee un rasgo de conciencia interior propia del enfoque Vivencialista-Introspectivista, este parte desde Platón en la filosofía antigua -Griega- y, San Agustín en la filosofía medieval en el periodo patrístico.

En síntesis, la filosofía antigua y medieval han contribuido a la construcción de los enfoques epistémicos o paradigmas tradicionales y emergentes, forjando de esta manera el devenir de la historia de la filosofía y ciencia moderna.

\section{Las corrientes filosóficas del pensamiento moderno y contemporáneo y, su influencia en los enfoques epistémicos o paradigmas investigativos tradicionales y emergentes}

Las corrientes filosóficas del pensamiento antiguo surgieron aproximadamente entre los siglo VII a.c y IV d.c y, la medieval entre los siglo II al XV. Posterior a estas, emergen en 
el siglo XIV las corrientes filosóficas del pensamiento moderno, conocido como el renacimiento, este tuvo su génesis en Italia y se extendió por toda Europa, teniendo un auge significativo entre los siglo XV y XVI (Marías, 1980).

El periodo moderno o renacentista, posee unas características que los distinguen de los dos anteriores; su filosofía es centrada únicamente en la razón, prescinde de la fe, al hacer esto, Dios no es considerado como el centro del universo y, originador de todo,incluyendo el conocimiento-, el pensamiento y el conocimiento dejan de ser teocéntrico, producto a esto, el hombre toma importancia significativa, es considerado como el centro, en este contexto, el pensamiento y el conocimiento se constituyen antropocéntrico (Marías, 1980).

A partir de esta nueva o moderna concepción filosófica se aborda el problema del conocimiento, a saber, su veracidad, obtenida a través de la capacidad del ser humano para descubrir la verdad; este asunto es caracterizado en la filosofía moderna como gnoseología. En el desarrollo de la filosofía moderna se gestaron disimiles teorías del conocimiento, entre las principales se encuentran: el racionalismo, el empirismo y, el idealismo (Marías, 1980). En lo inmediato las abordaremos de manera sucinta.

Racionalismo. Esta corriente filosófica se desarrolló aproximadamente entre los siglos XVII y XVIII, sus representantes significativos fueron: René Descartes, siendo este el principal, Baruch de Spinoza y, Leibniz; esta corriente estableció como premisa la razón para el conocer, a saber, -la razón- es el medio que legitima el conocimiento que adquiere el ser humano permitiéndole descubrir la verdad, por lo que, a la razón se le debe tener plena confianza, caso contrario a los sentidos, porque estos nos engañan. Asimismo, sostuvo que el ser humano posee ideas innatas, a saber, algunas ideas son independientes de la experiencia, son propias de nuestra mente, por consiguiente, consideró la aplicación de un método matemático-geométrico-deductivo, por poseer este la capacidad de mostrar verdades incuestionables, y además, de ser universal (Marías, 1980). 
Empirismo. Esta filosofía se desenvolvió aproximadamente entre los siglos XVII y XVIII, sus principales representantes fueron: David Hume, John Locke y, George Berkeley, esta corriente se opone al racionalismo, establece que la experiencia es la génesis del conocimiento que posee el ser humano, a saber, la experiencia es el único elemento válido para adquirir el conocimiento, también plantea, que la mente humana es una tabla rasa que se irá llenando de conocimiento en virtud a la experiencia, en tal sentido, la experiencia es la única fuente para llegar a la verdad; teniendo en cuenta que el conocimiento del hombre es limitado por la experiencia. El método usado por esta corriente es el inductivo (Marías, 1980)

Idealismo. Esta corriente filosófica tuvo su devenir entre los siglos XVIII y XIX, sus autores representativos fueron: Immanuel Kant y, Friedrich Hegel. Kant en su filosofía establece una vinculación o síntesis entre las dos corrientes filosóficas modernas principales; -el Racionalismo y Empirismo-. Al respecto, expresaba que la experiencia es la forma en la que se puede conocer las cosas, sin embargo, asimismo consideraba que la mente es la estructura en la que se fundamenta los principios básicos de la ciencia, por lo que, sostenía que ambas son dos formas disimiles de realismo, a saber, su interés está en el objeto. A diferencia de esto, la filosofía Kantiana centra su interés en el sujeto, -hombre cognoscente- que construye y estructura el objeto y la realidad en su mente a partir de la razón y la experiencia, esto le permite constituir las ideas de las cosas (Marías, 1980).

Por su parte, Hegel planteaba en su filosofía que la realidad es un todo, a esta realidad la consideró como lo absoluto o espíritu absoluto, en este sentido, sostuvo que la estructura racional interna de lo absoluto debe estar clara, la naturaleza y la historia humana es una demostración de lo absoluto y, la naturaleza de lo teleológica de lo absoluto de ser capaz de explicarse. A partir de esto, la filosofía hegeliana considera que se construye las ideas de las cosas (Marías, 1980).

Es claro que la filosofía y ciencia moderna delimitaron o definieron las corrientes filosóficas del pensamiento moderno, a saber, -el racionalismo, empirismo e 
idealismo- conocidas estas en la contemporaneidad como enfoques epistémicos o paradigmas investigativos tradicionales. Al igual que en el apartado anterior, pero, sin entrar en detalles por estar expuesto allá, es preciso mencionar que las corrientes filosóficas modernas han influenciados los enfoques epistémicos o paradigmas investigativos emergentes, tal es el caso del constructivismo y conductismo. El conductismo es derivación del empirismo-inductivista, este paradigma emergente permite la generación del conocimiento a partir de la conducta observable asociada a la experiencia, al igual que el positivismo, el interés de este está en los datos, en los hechos observables, la realidad es captada por los sentidos. El constructivismo es una continuación del realismo/idealismo, en este el sujeto construye a partir de la realidad y del objeto.

Otro paradigma emergente es el estructuralismo, este caso lo detallaremos de forma sucinta, al respecto, Lévi-Strauss (1973) consideró al estructuralismo como una construcción racional del pensamiento, a saber, el análisis o razonamiento de un fenómeno para determinar su apariencia, componentes y coherencia, con el propósito de conocer su estructura. El estructuralismo procura determinar racionalmente cómo está construida la estructura de un fenómeno y como se interrelaciona sus componentes entre sí, logrando identificar el parentesco de cada elemento que la constituyen.

El estructuralismo es una prosecución del racionalismo-deductivista, este tiene su premisa en representar estructuras mentales de un fenómeno, a saber, determinar mediante la mente su funcionamiento interno, sin la necesidad de observarlo con los sentidos.

En concreto, las corrientes filosóficas y ciencia del pensamiento moderno han influenciado de manera significativa en los enfoques epistémicos o paradigmas investigativos emergentes, contribuyendo de esta manera el devenir de la historia de la filosofía y ciencia contemporánea. 
Ahora bien, el pensamiento filosófico y ciencia contemporánea, en algunos textos especializados se les denominan paradigmas emergentes, recibieron influencias significativas de las corrientes filosóficas y ciencia del pensamiento moderno. Tal es el caso del positivismo, expuesto en apartados anteriores, en esta oportunidad expondremos algunos detalles, al respecto, considera que es la ciencia la fuente de todo conocimiento verdadero, adquirido a partir de los hechos de experiencias, en esta misma línea encontramos al neopositivismo, por supuesto con algunas particularidades; ambos derivan del empirismo.

En la contemporaneidad también surgió la filosofía analítica, esta procura aclarar el lenguaje y analizar los conceptos contentivo en el, por lo que considera, la premisa de toda filosofía es aclarar el lenguaje, esta corriente fundamenta el conocimiento en la experiencia, es conocida también como empirismo lógico, es evidente la influencia del empirismo en este pensamiento filosófico.

Asimismo, surge la fenomenología, esta corriente busca ampliar el horizonte de la experiencia humana, con el propósito de adquirir el conocimiento de las esencias humanas en los ámbitos: ético, religioso, estético, etc., en este caso, el empirismo también marca su influencia.

En el marco de la filosofía contemporánea emerge el Círculo de Viena, su intencionalidad principal es establecer una filosofía científica, para ello, la fundamentan en el empirismo lógico o neopositivismo, a saber, todo conocimiento científico debe fundamentarse en la experiencia. Es claro que el Círculo de Viena estaba influenciado por la corriente filosófica empirista.

En definitiva, las corrientes filosóficas y ciencia del pensamiento contemporáneo, al igual que el moderno, han influenciado de manera significativa en los enfoques epistémicos o paradigmas investigativos emergentes, construyendo de esta forma la prosecución del pensamiento filosófico emergente en el desarrollo de los procesos investigativos. 


\section{La Influencia del pensamiento emergente en el desarrollo de los procesos investigativos}

En el pensamiento moderno, conocido como el renacimiento, se desarrollaron distintas teorías del conocimiento, entre las principales se encuentran: el racionalismo, el empirismo y, el idealismo (Marías, 1980). Estas influenciaron los enfoques epistémicos o paradigmas investigativos emergentes, a saber, el constructivismo, conductismo, estructuralismo, positivismo, neopositivismo, filosofía analítica, fenomenología, etc., estas últimas han influenciado el pensamiento emergente en el desarrollo de los procesos investigativos.

Estos enfoques epistémicos surgidos después del renacimiento, sirvieron de fundamentos para el nacimiento del pensamiento emergente, a saber, un cambio de enfoques epistémicos o paradigmas, al respecto, Beynam (1978) plantea, en el contexto actual estamos frente a un cambio de paradigma en la ciencia, posiblemente este sea un cambio de importancia significativa producido a la fecha, además, posee la ventaja de proceder de la física contemporánea, está surgiendo un nuevo paradigma que ejerce influencia en todas las áreas del conocimiento; este nuevo paradigma no desecha los postulados de Galileo, Newton o Descarte, por el contrario, los integra en perspectiva amplia y mayor sentido.

Por lo visto, en nuestro contexto científico estamos enfrentando un nuevo paradigma, que deja ser mecanicista, reduccionista y particular, que emerge para constituirse integrador de las disímiles disciplinas y poseedor de una visión claramente interdisciplinaria. El paradigma al cual hacemos referencia es el de la complejidad.

En tal sentido, Martínez (sf) expresa lo siguiente, cada uno de nosotros somos un "todo físico-químico-biológico-psicológico-social-cultural" con un funcionamiento maravillo que es constituyente de nuestra vida y ser, es por ello, el ser humanos debe ser considerado la estructura dinámica o sistema integrado más complejo de todos los 
existentes en el universo, en esta misma línea de ideas, los hombres de ciencias profundamente reflexivos, de las distintas áreas del conocimientos, biólogos, neurólogos, antropológicos o sociológicos, asimismo, los físicos y matemáticos, en su conjunto, procuran superar, implícita o explícitamente, la visión reduccionista y mecanicista del antiguo paradigma newtoniano-cartesiano y, desarrollar este nuevo paradigma, a saber, el de la complejidad.

Según Morín, considerado el padre del paradigma de la complejidad, sostiene, que es el fundamento organizador que nunca pierde de vista la realidad del tejido fenoménico donde nos desenvolvemos, que a su vez constituye nuestro mundo, aun cuando este sea enorme podemos tratar de gobernarlo mediante nuestra regulaciones. Así mismo, considera, la complejidad busca las relaciones inter y retro de las acciones entre los fenómenos y su contexto, la reciprocidad de las relaciones entre el todo y las partes, cómo un cambio local afecta el todo, y cómo un cambio en el todo afecta lo local o las partes (Morín 1990).

Por consiguiente plantea, la racionalidad compleja es el reconocimiento de la subjetividad y la búsqueda de la objetividad, la concreción de un todo organizado, de lo complejo a lo singular y simple de un todo, la armonía en el trabajo de los elementos de un todo; "es el desarrollo autocritico de la tradición critica que no solo reconoce los límites de la racionalidad, sino también los peligros siempre renacientes de la racionalización, es decir, de la transformación de la razón en su contrario; es el desarrollo de una razón abierta, que sepa dialogar con lo irracionalizable" (Morín 1994: 191). Este paradigma emergente ha recibido influencia significativa del racionalismo, sin embargo, producto a su alcance complejo, multidimensional e interdisciplinario propio de su naturaleza, también hace uso del empirismo e idealismo. Asimismo, procura hacer una síntesis de los paradigmas emergentes anteriores a él.

Otro paradigma emergente o pensamiento surgido en nuestro contexto de la ciencia, es el decolonial, este se fundamenta en la separación de las teorías críticas, asimismo, de la eurocéntricas surgida en la modernidad, su visión latinoamericana, su naturaleza, 
análisis y estrategias metodológicas, conciben a esta corriente filosófica independiente, emancipadora y enriquecedora para la libertad de un conocimiento propio latinoamericano, capaz de aperturar desde el rigor colonial, una desconstrucción de la modernidad-colonialidad (Dussel, 2000).Este paradigma, al igual que el de la complejidad, posee influencia del racionalismo, empirismo e idealismo, sin embargo, utiliza estos enfoques epistémicos desde la perspectiva Latinoamérica con un énfasis propio.

En síntesis, estos pensamientos emergentes, han influenciado los procesos investigativos de nuestro contexto científico, a saber, en el pensamiento o paradigma de la complejidad y, en el decolonial en el marco latinoamericano; por consiguiente, el pensamiento complejo es utilizado en el decolonial desde la perspectiva latinoamericana.

\section{Metodología aplicada}

Dentro del marco metodológico, hemos utilizado la investigación de tipo documental. Al respecto, Méndez (2001) plantea, la investigación documental es una forma de la investigación científica, su objetivo esencial es el análisis de disimiles fenómenos de la realidad mediante la indagación exhaustiva, sistemática y rigurosa, haciendo uso de técnicas precisas; de la documentación existente, que directa o indirectamente, aporte la información en relación al fenómeno que estudiamos.

Asimismo, aplicamos el paradigma interpretativo, este enfatiza lo profundo en lugar de lo superficial, lo intenso en lugar de lo extenso, lo particular en lugar de las generalizaciones, la adquisición del significado y del sentido interno, subjetivo, de forma previa a la observación exterior de supuestas regularidades objetivas (Vasilachis, 2009).

Por consiguiente, hicimos uso del análisis del discurso, este es una herramienta que facilita el entendimiento de las prácticas discursivas que se generan en todas las esferas de la dinámica de la vida social, en las que el empleo de la palabra oral o 
escrita se constituye parte de las actividades que en ella se desarrollan (Calsamiglia y Tusón 1999). Respecto a la interpretación del análisis del discurso (Navaja 2009) establece, en términos generales, el análisis del discurso lo consideramos como una práctica interpretativa que aborda a todos los discursos y en correspondencia a los problemas de los que parta hace uso de una u otras disciplinas lingüísticas y no lingüísticas.

Esta metodología en el marco de la investigación documental, interpretativa y descriptiva, empleando como método de análisis, el análisis del discurso; procura caracterizar el hecho investigado, con el objeto de determinar sus elementos fundamentales, por lo tanto, se efectuó una revisión sistemática con criterio crítico de la información del problema a investigar, a un conjunto de textos especializados para abordar y ampliar los conocimientos respecto al tema.

\section{Conclusiones}

La filosofía antigua y medieval ha influenciado de manera significativa en el desarrollo de los enfoques epistémicos o paradigmas tradicionales y emergentes, constituyéndose de esta manera en sus antecedentes filosóficos y epistemológicos.

Las corrientes filosóficas y ciencia del pensamiento moderno y contemporáneo, han influenciado significativamente a los enfoques epistémicos o paradigmas investigativos emergentes, estableciéndose de tal forma, en sus fundamentos filosóficos y epistemológicos.

Los pensamientos emergentes han ejercido influencia en los procesos investigativos de nuestro contexto científico, a saber, son la génesis y constitución del pensamiento o paradigma de la complejidad, asimismo, del pensamiento o paradigma decolonial latinoamericano, este a su vez, hace uso del pensamiento complejo.

Existe una influencia y correlación entre las Corrientes filosóficas del pensamiento antiguo, medieval, moderno y contemporáneo, y los enfoques epistémicos o 
paradigmas investigativos tradicionales y emergentes, asimismo, estos en el desarrollo de los procesos investigativos de nuestro contexto científico.

\section{REFERENCIAS CONSULTADAS}

1. Abbagnano, N. (1994) Historia de la filosofía, vol I: Filosofía antigua, filosofía patrística, filosofía escolástica, Editorial Hora S.A., 4ª edición, Barcelona.

2. Calsamiglia, H. y Tusón, A. (1999). Las cosas del decir. Manual de análisis del discurso. Barcelona, España: Ariel.

3. Dussel, E.(2000): "Europa, Modernidad, y Eurocentrismo", en Lander, E. (comp.); Op. Cit.

4. Ferrater, J. (1994): Diccionario de Filosofía. Tomo I, A-K. Sudamericana Buenos Aires.

5. Hernández, A. y Padrón, J. (1997): Referencias Básicas en la Producción de una Tesis Doctoral. San Juan de los Morros: Colegio de Economistas.

6. Kuhn, T. (1971) La Estructura de las Revoluciones Científicas. FCE. México, D.F.

7. Lévi-Strauss, C. (1973). "El campo de la Antropología" en Antropología Estructural. Siglo Veintiuno de España Editores.

8. Marías, J. (1980): Historia de la filosofía. Biblioteca de la Revista de Occidente.

9. Martínez (sf). El paradigma emergente.

10.Méndez, C. (2001). Metodología. Diseño y desarrollo del proceso de investigación. Colombia: McGraw-Hill.

11.Morín, E. (1990). Introducción al Pensamiento Complejo. España: Editorial Gedisa.

12.Morín, E. (1994) El Método III. El conocimiento del conocimiento, Madrid, Ediciones Cátedra.

13. Navaja, E. (2009). Análisis del discurso. Modos de abordar materiales de archivo. Santiago Arcos editor. Argentina. 
KOINONIA. Revista Arbitrada Interdisciplinaria de Ciencias de la Educación, Turismo, Ciencias Sociales y Económica, Ciencias del Agro y Mar y Ciencias Exactas y

14.Padrón, J. (2014): Proyecto de Epistemología en DVD. Doctorado en Ciencias Humanas, Maracaibo: La Universidad del Zulia.

15. Real Academia Española. (2001) Diccionario de la lengua española, $22^{0}$ Edición. Edit. RODESA, Madrid-España.

16. Vasilachis, I. (2009). Métodos de la investigación cualitativa. Barcelona, España: Gedisa.

(C2019 por el autor. Este artículo es de acceso abierto y distribuido según los términos y condiciones de la licencia Creative Commons Attribution (http://creativecommons.org/licenses/by/4.0/). 